\title{
Irreversible Time and Entropy in Thomas Pynchon's The Crying of Lot 49
}

\author{
By Lovorka Gruic Grmusa*
}

\begin{abstract}
Keeping in mind that both science and literature bring complementary endeavors in the process of perception and creation as well as in the world through which those processes take part, this article deals with irreversible time and entropy as presented in Thomas Pynchon's The Crying of Lot 49. Even though Pynchon acknowledges the entropic pull and consequently the dissipation of energy, he also regards entropy in Claude Shannon's terms, as a proliferation of information. In this sense, the system gets activated toward increasing complexity rather than heat death, juxtaposing it to chaos theory so that its underlying principle encompasses both renewal and dissolution. In Pynchon's vision, just as closed mechanical systems gradually lose energy and dissipate, so do societies run down, tend toward disorder, and ultimately collapse if there is no input of external energy. Yet, despite the menacing, official notion of entropy as the irreversible movement toward the absolute end of time, Pynchon's novel shows systems' "correspondences" with their surroundings, which gives them new possibilities. Open systems are in a better position because they can evolve with the arrow of time facing forward. Consequently, as the paper argues, information (recognized as disorder) is growing so rapidly that the systems get overloaded, distorted, and buried in noise, augmenting the main character's (who acts as a "demon" and sorts out information) confusion and the systems' complexities.
\end{abstract}

Keywords: Entropy, Information, Irreversible time, Self-organization, Thomas Pynchon

If we conceive a being whose faculties are so sharpened that he can follow every molecule in its course, such a being, whose attributes are still as essentially finite as our own, would be able to do what is impossible for us. For we have seen that the molecules in a vessel full of air are moving at velocities by no means uniform [...]. Now let us suppose that such a vessel full of air at a uniform temperature is divided into two portions, $\mathrm{A}$ and $\mathrm{B}$, by a division in which there is a small hole, and that a being, who can see the individual molecules, opens and closes the hole, so as to allow only the swifter molecules to pass from A to B, and only the slower ones to pass from B to A. He will thus, without expenditure of work, raise the temperature of $\mathrm{B}$ and lower that of $\mathrm{A}$, in a contradiction to the second law of thermodynamics (Maxwell 1871: 328).

\section{Introduction: Entropy and "Demons" that Reduce Dissipation}

With a history dating back to antiquity, there were serious attempts to construct a machine that gives something for nothing - a perpetual motion machine. Perpetual motion refers to a condition in which an object moves forever without the expenditure of any limited internal or external source of energy, which in the context of temporality discourse means that it would discard entropy and allow the reversibility of time (Davies 1995: 84). However, the second law of thermodynamics states that such perpetual motion is doomed to fail. Time has an arrow that goes toward only one direction: the future. The first law states that

\footnotetext{
${ }^{*}$ Associate Professor, Faculty of Humanities and Social Sciences, University of Rijeka. Croatia.
} 
energy cannot be produced from nothing: it remains constant, conserved within a closed system. The second law declares that some amount of energy is lost forever as the system works, turning into an unusable energy/state, so that the amount of entropy in the universe tends to increase. Rudolf Clausius, a German physicist who stated these laws in 1865 applied the name "entropy" (from Greek: energy and transformation) to the law regulating the transfer of heat from one body to another (Holton 1973: 291). When energy is dissipated as heat, it cannot be regained, so every closed system has a tendency toward a state of total disorder (in old fashioned terms - chaos).

As cited in the quotation at the beginning of this paper, the famous physicist James Clerk Maxwell envisioned a tiny being, which he calls a Demon, that can control dissipation of energy by separating fast molecules from slow ones in a closed system, so that the entropy would decrease. Although Maxwell's idea, if correct, would do miracles for humanity by stopping the "heat death" that unleashes slowly as time passes, from the scientific point of view, as Katherine Hayles states: "the story is a scandal, for the "being" turns out to be a demon who demands the sacrifice of a scientific truth as the price for his intervention" (Hayles 1990: 43).

Thomas Pynchon's The Crying of Lot $49^{1}$ tackles the phenomenon of entropy and introduces both a mechanical and a human information sorter, or demon, which strive to reduce the dissipation of energy. The mechanical demon apparently exists in the so called Nefastis Machine, which is based on James Clerk Maxwell's idea and suggests that information collected by the demon can neutralize the natural entropy of a closed system and produce perpetual motion. However, as the main character-Oedipa finds out, the machine does not work. The human information sorter that is the focus of Pynchon's novel is Oedipa herself, who desperately tries to sort out and make some order out of the overwhelming (dis)information that she receives. However, she is unable to gather unquestionable facts or meaningful information that could conclude her search. The reader witnesses how information proliferates too rapidly, affirming the uncontrollable speed of the contemporary world and the perpetual transformation of materials and intelligence compiled. Oedipa proves helpless in making sense of the data she obtains. She recovers fragments of the past so that they may serve as evidence, but they turn into a genie in an endless hermeneutic circle of her search. Pynchon stresses that time is irreversible, which Oedipa perceives as a negative property for she is not capable of forming meaning out of the immense information that she encounters as the time passes.

Thus, this article links temporality with entropy, disorder, information, and self-organization as perceived in Thomas Pynchon's The Crying of Lot 49. The novel delineates an intriguing argument, in agreement with Claude Shannon's (1948) information theory and Ilya Prigogine's (1997) take on chaos theory (theory of dissipative structures). Its argumentative discourse supports the idea that systems rich in entropy abound in information. Such chaotic, far from equilibrium systems seem disordered precisely because they contain overwhelming amounts of information. These systems could "evolve" toward "increasing complexity rather

\footnotetext{
${ }^{1}$ The Crying of Lot 49 is hereafter marked as LOT.
} 
than dissolution" (Hayles 1991: 111-112) by engaging in self-organization where irreversible temporality sustains systems' existence. Their structures can release order out of chaos - which is why Prigogine calls them "dissipative structures" (Prigogine 1997: 73) — testifying that time has an arrow facing the future, which is not as negative as thermodynamic entropy reveals/predicts, but consists of positive, life-sustaining powers that compensate for the negative, unquestionable entropic pull. This means that even though perpetuum mobile does not exist, there is a "natural demon" within nonlinear systems, acting in enigmatic ways, which preserves their survival.

\section{Pynchon's Entropic World}

Pynchon has been fascinated with entropy from the very beginning of his career, emphasizing that entropy is an abundance of information: "Pynchon has already sensed that disorder, conceived as maximum information rather than dissipation, could offer an exit from the traditional "'exitlessness' of heat death scenarios" (Hayles 1991: 112). However, Pynchon's take on entropy, tackled in all of his texts, suggests that it is a difficult concept to grasp and one metaphorically suitable to many aspects of life. As he claims in the discussion of his early work Entropy: "Since I wrote this story, I have kept trying to understand entropy, but my grasp becomes less sure the more I read" (Pynchon 1984: 14).

In his short story Entropy, Pynchon addressed this phenomenon for the first time, juxtaposing an open chaotic system that is active and vibrant with an apparently "closed," desolate, and unproductive system. The "closed" system features Callisto and Aubade, characters who like Oedipa try to stop time from passing, "paranoids" who, as in most of Pynchon's texts, "quest for a transcendent meaning in a chaotic world whose energy seems to be running down" (Mackey 1980: 3). Callisto is obsessed with heat death and paralyzed with the idea of increasing entropy. He does his best to stop time from passing, for which he and his girlfriend, Aubade, get enclosed within an apartment, sealed off from the outside world in a sort of a

hothouse jungle it had taken him seven years to weave together. Hermetically sealed, it was a tiny enclave of regularity in the city's chaos, alien to the vagaries of the weather, of national politics, of any civil disorder (Pynchon 1984: 83-84).

They try to stop the inevitable: time from ticking toward the future, change, and death. The readers find Callisto in bed holding a sick bird, hoping to sustain the bird's life by transfer of heat from his body. Aubade constantly checks the outside temperature, which has been 37 Fahrenheit for the past three days. The couple fears that the stable temperature is the sign of the heat death of the universe, the point of maximum entropy. When the bird dies, they assume that heat transfer is not possible any longer, for the universe has reached thermodynamic equilibrium and entropy is at its maximum.

Meanwhile, in the apartment downstairs, Meatball Mulligan's party, crowded with bureaucrats and pseudo-intellectuals, was moving into its fortieth 
hour. People were constantly coming in, invited or uninvited, drinking and behaving in a disorderly manner, and thus revealing the vivacity of an open system. Meatball considered hiding and locking himself in a closet (a hint to Callisto's enclosure), but instead he decides to act as a "demon" and sort things out. He calms people down, addressing each person with patience, cleans up the apartment, helps the girl in the shower "from drowning," and sends away the drunks. With this input he has regulated the system, which now seems far from disorder, as well as far from the entropic pull, keeping in mind that this system is open, with fresh energy coming in at all times.

The inconsistencies in the theory and understanding of entropy (that Pynchon underlined in the criticism of his own texts) are particularly pronounced in this story. Pynchon clearly used two apartments to situate two separate theories of entropy: thermodynamic and informational. In Meatball's apartment, informational entropy dominates for the system is lacking order and is rich in information. Callisto's residence appears pristine and well organized, correlating with the world of thermodynamic entropy, progressing toward uniformity and equilibrium, or "the final absence of all motion" (Pynchon 1984: 98), following his own reductive ontology. Scientifically, the two concepts of entropy are dimensionally unequal, because thermodynamic entropy deals with energy and temperature, whereas informational entropy administers units of information. They can even

be seen as inversions of each other. In other words, at maximum thermodynamic entropy, systemic uniformity results in minimum information and maximum certainty. Information entropy and the uncertainty it measures are therefore at a minimum. Conversely, at minimum thermodynamic entropy, systemic differentiation results in maximum information and minimum certainty. Uncertainty is then at a maximum, and information entropy is at a maximum as well (Kharpertian 1990: 102-3).

However, the two concepts of entropy are sometimes related, as in Boltzmann's equation (to be presented later), the resemblance which Nefastis, the scientist character from LOT, calls a "coincidence" and claims their connection only "at one point: Maxwell's Demon" (LOT 105).

To explain further, Mulligan's system is depicted as more open, like Oedipa's, and it is teeming with information of all sorts, which seems rather overwhelming for a single party. He gets bombarded with guests and data (just like Oedipa does), and finally decides it has been too much, acting to stop the overflow as he makes some order (for a while, anyways). The more closed system at Callisto's ${ }^{2}$ is depicted as closer to balance and homeostasis, with all the plants and little animals living together with two humans. As such (science tells us), it is more prone to the entropic pull because of its closure and equilibrium. However, the open system at Mulligan's is illustrated as the one tending towards higher entropy — considered as disorder — with unwanted and inebriated guests mingling and behaving in a disorderly manner. Even when they run out of liqueur,

\footnotetext{
${ }^{2}$ We can say that it is not a completely closed system since they have food delivered from the outside to the apartment.
} 
some sailors arrive and bring new supplies/energy from the outside. Yet, in terms of information theory, Mulligan's apartment, although disorderly, abounds in information. Thus, this far from equilibrium system actually has a greater chance of surviving the arrow of time for it "interweaves" with its surroundings, allowing new patterns to produce its evolution.

The issues concerning entropy continue in Pynchon's LOT, which symptomatically begins with news of a death, a demise of Pierce Inverarity who named his former lover Oedipa Mass the executor of his will, the novel teeming with clues, innuendos and ambiguity right from the start. This opening is indicative of the tone of the novel, which insists on negative entropic value of decay and delineates that the main character is consumed with the overflow of information that changes and disappears with time. Pierce's dissolution triggers an inquiry on Oedipa's part, an odyssey that takes her much further than the readers might have thought, into the post-Renaissance European history, although from the perspective of "the zany Southern California of the sixties" (Brigg 2002: 83). Trying to sort out the slippery clues that she assembles, running around California to get more data and testimony about the mysteries that surround Pierce's estate, gets her to the path of the Tristero (or Trystero). The Tristero represents "the long history of an underground resistance movement that seems to exist for the purpose of providing different ways to communicate information" (Hite 1983: 29), a force that demands some order in the chaotic universe:

If it was really Pierce's attempt to leave an organized something behind after his own annihilation, then it was part of her duty, wasn't it, to bestow life on what had persisted, to try to be what Driblette was, the dark machine in the centre of the planetarium, to bring the estate into pulsing stelliferous Meaning (LOT 81-82).

However, as Schaub notes, "reaching the real message [...] is blocked by the transformations of time: variant texts, pirated copies, faulty memory and questionable interpretation" (Schaub 1981: 62), which prevent information from staying the same and producing what Oedipa believes is its true or intended meaning.

A close parallel to Oedipa's unraveling of the scattered information is Maxwell's Demon, the molecular information sorter supposed to exist in the Nefastis Machine, a device that apparently violates the second law of thermodynamics so that the system is said to lose entropy. The Demon is described as a tiny intelligence that could

sit in a box among air molecules that were moving at all different random speeds, and sort out the fast molecules from the slow ones. Fast molecules have more energy than slow ones. Concentrate enough of them in one place and you have a region of high temperature. You can then use the difference in temperature between this hot region of the box and any cooler region, to drive a heat engine. Since the Demon only sat and sorted, you wouldn't have put any real work into the system. So you would be violating the Second Law of Thermodynamics, getting something for nothing, causing perpetual motion (LOT 86). 
In order to work, Nefastis's invention needs the cooperation of a human "sensitive": "Communication is the key. [...] The Demon passes his data on to the sensitive, and the sensitive must reply in kind. [...] The sensitive must receive that staggering set of energies, and feed back something like the same quantity of information" (LOT 105). Although Oedipa tries to make the machine work, she fails, which additionally inflames her fear of mortality. Her pursuit is connected to the overall angst and avoidance of death through wills, sexual abstinence, and attempted séances with the deceased, but also to her "attempts to impose meaning on human mortality" (York Blaine 2003: 55). This culminates in Oedipa's realization that death is an "irreversible process" (LOT 128) because time has an arrow that only moves forward, and we can do nothing about it. No matter how much she rushes around accumulating data, it changes and disappears faster than she can balance and connect any of it firmly together, thus proving that perpetuum mobile does not exist, neither in mechanical nor human forms.

Her lover has left her nothing material, and instead only hints to an enigma called the Tristero that she desperately tries to unravel by meeting unusual characters who give her some clues to the invisible organization. Nevertheless, " $[\mathrm{t}]$ he more connections and interconnections she makes, the greater the disorder of entropy generated" (Harvey 2013). The data that she collects turn elusive and the "witnesses" disappear, have second thoughts, go mad, and commit suicide. Entropy does not cease and time moves on. As Copestake notes, Oedipa finds herself in "a new world of deconstructed truths and textual meanings in which she must try to make herself at home" (Copestake 2005: 174).

The Tristero System, a conspiracy of underground information transmission that has allegedly functioned since the Middle Ages, gives Oedipa hope. It might offer historical continuity and integrate various events described in the novel if she were only able to stop time and put it in order (if only the "demon" existed). It promises there may be a way to stop the entropic pull by exchange of information. Indeed, communication is not lacking in the novel; in fact, it is just the opposite. There are various means of correspondence, intercourse, transfer, transmission, signs and symbols that demand acute perception, dissection, reasoning, interpretation, and analyses. All these yield mixed/different messages, so that it leads to confusion and not revelation, sustaining the persistence of the arrow of time. As Hayles remarks:

too much information, piling up at too fast a rate, can lead to increasing disorder rather than order. [...] What we fear most immediately is not that the universe will run down, but that the information will pile up until it overwhelms our ability to understand it (Hayles 1990: 49).

It is even possible that the systems (various editions of the Jacobean play and mail distribution companies) that Oedipa devotedly tries to decipher exist only because she is keeping them "viable" by her sorting. This implies the importance of language, communication, and history. No wonder the systems transform through the centuries since "demons," "sensitives," or just people that record reality change with every generation, and there is a multiplicity of them 
sorting various systems. A system or a past can never remain completely isolated from other systems or pasts (as documented or remembered by other people); nor can it remain unchanged, for it must stay in a dynamic relationship so that it "survives". The passage of the past is not principally introduced by thoughts, but by nature itself. It pertains to the universal becoming, complementing the emergence of new events and the expanding of the universe, which makes our reality complex and interesting. It might also be as Whitehead pointed out that how we perceive reality is only our fabrication: "The physical world", he writes, "is in some general sense of the term, a deduced concept" (Whitehead 1929: 247).

Before going any further with the interpretation of the entropic force and Oedipa's efforts to stop it and make some meaning out of collected information, a closer look into Claude Shannon's information theory should be taken. It states that information and entropy are not really opposites, but rather are closer to equivalents because proliferating information is associated with the production of entropy. In other words, the potential gain in information is larger when the system has more entropy (Shannon 1948: 13-14). One of the earliest papers on Pynchon and his ideas about entropy by Anne Mangel discloses Shannon's equation where:

$$
\begin{aligned}
& \text { average information/symbol= }-\underset{\mathrm{j}}{-\mathrm{pj} \log \mathrm{pj}} \\
& \text { is equal to Boltzmann's equation of entropy: } \\
& \mathrm{H}=-\underset{\mathrm{j}}{\mathrm{pj}} \log \mathrm{pj} \\
& \text { (Mangel 1976: 94) }
\end{aligned}
$$

In Shannon's view, systems rich with entropy are indeed disordered. However, that means they are rich in information, driving the systems far from equilibrium, increasing in complexity, and displaying irreversible temporality.

These "two kinds of entropy, thermodynamic and informational" (LOT 109) are clashing into each other while Oedipa separates "noise" from useful data in her own terms. Noise is considered to be all that interferes with the reception of the message that was sent. The intrusion of noise into the information channel distorts the signal and changes the meaning. As Shannon notes, "there are a number of entropies that can be calculated," such as those of the source or input, of the output to the channel and of their relations (Shannon 1948: 19). The more information, the more noise - so that with time, there is less meaning instead of more. As Kharpertian explains: "In cybernetic terms," Oedipa moves "from lesser to greater entropy, as the multiplicity of information she gathers about the Tristero increases the uncertainty of the information's ultimate significance" (Kharpertian 1990: 104). The distortion of the signal, and therefore meaning, is observed by Mucho Maas, a disc jockey who is Oedipa's husband. During an interview with Oedipa, he considers the changes his words will undergo during the radio transmission, and in order to neutralize the distorting effects, he deliberately mispronounces her name: "Thank you, Mrs Edna Mosh" (LOT 139). Oedipa is surprised, but Mucho explains: "It'll come out the right way [...]. I was allowing for the distortion on these rigs, and then when they put it on tape" (LOT 139). 
The novel stresses the importance of the perceiver, for every perceiver is simultaneously an observer and a handler (which is another reason why entropy distorts the original text, or better said, proves that information is entropic). When Oedipa watches the play The Courier's Tragedy for which she finds various scripts with changes of lines, she again wants to get the true version, to be able to interpret the first pure meaning. The absolute meaning is always postponed though, even at the end of the novel, for there is no reversibility of time. As Leigh notes: "The novel ends with her waiting in hope of finding a definite answereither/or-to her quest for ultimate meaning" (Leigh 2008: 56). Yet, the mysterious bidder is not revealed and the written sources are reproduced and changed. Some of the editions of the play are, as professor Emery Bortz tells her, pirated or corrupt, and the one in the Vatican is pornographic, with no one agreeing "about the meaning of the play, the author's intention, or the larger sociopolitical situation that engendered it" (Slethaug 2000: 39).

One of the lines that attracts Oedipa's attention is: "No hallowed skein of stars can ward, I trow, / Who's once been set his tryst with Trystero" (LOT 75). While trying to understand the meaning, she comes across an edition from 1687 where the second line reads: "Who once has crossed the lusts of Angelo" (LOT 102). In the Whitechapel edition from 1670, it is changed to: "This tryst or odious awry, O Niccolo" (LOT 102). This demonstrates the almost complete transformation of key lines, and reminds us that Oedipa alone decides which evidence constitutes clues for her to follow. As the flow of information increases, Oedipa is forced to speed up and discard information that she finds irrelevant. To an "unbiased" observer (if such exists) this may seem that she sorts the data randomly, in a way that it is presented to her, so that she follows the connotations in some cases and disregards them in others, with such speed that it grants entropic pursuit.

Driblette, the director of the play argues that it is his function

To give the spirit flash. The words, who cares? They're rote noises to hold line bashes with, to get past the bone barriers around an actor's memory, right? But the reality is in this head. Mine. I'm the projector at the planetarium, all the closed little universe visible in the circle of that stage is coming out of my mouth, eyes, sometimes other orifices also (LOT 79).

He claims that the nature and the meaning of the performance are in his hands to shape according to his vision. He is partially right, for that momentum is all there is: all the pieces/lines/actions that make the play are "perfect" as it is right there and then. Yet, Oedipa will never find out what the play meant for the author or what the line difference represents, for she is unable to turn back time. Driblette provokes her with these words:

You can put together clues, develop a thesis, or several, about why characters reacted to the Trystero possibility the way they did, why the assassins came on, why the black costumes. You could waste your life that way and never touch the truth. Wharfinger supplied words and a yarn. I gave them life. That's it (LOT 80). 
The director was not precise enough because whatever he did to make the play alive, he was still just one of the vehicles. There were also the text and the actors, each projecting a trace of their individuality and making the play "complete," and of course the audience, including Oedipa. Each participant is interpreting the play on her/his own, weaving priorities and perceptions and drawing conclusions. However, Driblette was correct to say that she could seek for the truth forever and never get any closer to it. Time forces systems to change their "primary, truthful" states and pasts forever, remaining partial or hidden, granting new created pasts or no pasts at all.

The story of the previously mentioned lines does not finish here, for Oedipa picks up a version of it on the street while crossing Golden Gate Park, where she hears children play and rhyme: "Tristoe, Tristoe, one, two, three" (LOT 119). There are numerous hints as to what "Tristoe" can mean in this rhyme. It can be perceived as Tristero (the organization or the character from the play) or as "tryst" - an agreement between lovers. On the other hand, it is connected to the Italian word "triste" as Oedipa considers, which means "sad". The phrase can also be associated with "Trist's toe" since a children's game is in question. If derived from middleenglish "thrusten, thristen, thrysta", or just "thrust", one of the meanings is to pierce or stab with a pointed weapon (which Tristero does to Niccolo in the play). The same word and crucial lines are transformed according to "information sources used as input to the channel", but also how they are perceived, depending on the received signal: "the output entropy" (Shannon 1948: 22, 40). Through various editions and plays, and even a game, the word changes on its way to the perceiver. Furthermore, the perceiver, by affecting the information, contaminates and corrupts the original meaning with time.

Yet another term "Thurn and Taxis" (LOT 75), which Oedipa hears in the play, manifests how time dismisses and changes the past. Thurn und Taxis is a well known German aristocrat family who monopolized the whole postal system in Europe for three centuries, until the nineteenth century when Napoleon ceased the monopoly. Trying to find out the secret of the Tristero, she attempts to interpret this phrase, but ends up entangled in its different versions that complicate the Tristero mystery even more. The variants that she detects are: "Torre and Tassis" (LOT 157) and "Turning taxi from across the sea" (LOT 119). Oedipa concludes they are of Italian origin. The word "torre" means fortress in Italian, but it is more likely to be connected to the city of Turin (von Thurn), which is connected to "Tassis": the last name of the ancestors of this family dating back to the thirteenth century, when mail was distributed only within Italy. The word "taxi" was used for the horse-drawn coaches of the Thurn und Taxis family that were distributing goods and mail from town to town.

Oedipa is not able to get to the ultimate truth, the revelation that she is looking for, as the transmission causes disintegration and deviation of information. Plus, information increasingly multiplies, thereby sustaining Shannon's view that maximum information means disorder. Yet, Oedipa does not quit, thinking of herself as "the dark machine in the center of the planetarium" (LOT 82), desperately seeking to make order, stop the entropic decay, and form a pattern and meaning to the inheritance that Pierce has left her. As Brownlie notes: "She has been doing, however poorly, the Demon's task" (Brownlie 2000: 60), 
sorting and decoding information in systems that are rapidly growing out of her reach, following time's arrow and yet demonstrating certain recursion, just as "the dynamics of bifurcations reveal that time is irreversible yet recapitulant" (Briggs 1989: 145). As Carolyn Brown concludes: "caught in the spaces and times of the late twentieth century [...] [Oedipa] can only await the outcome, bearing within [...] the becoming of the new [...] the multiple" (Brown 2003: 159). She is saturated with the multiplicity of information and deeply aware of at least two separate realities, the current space-time that she inhabits and the one that she constantly stumbles upon, under the denomination of the Tristero, steadily permeating the real world.

However, as she discovers inconsistencies within the systems, she drops them one by one (the text and its editions, the postal service and its history), and moves on to other topics, somehow related but detached enough from what she was doing previously. Humans cannot store massive amounts of information as computers do, so we amuse ourselves for a short time with certain topics and then discard them, the systems of our interest competing all the time, demonstrating memory flaws. Our neural systems are complex, depending on, as Edelman and Tononi, two experts in neuroscience have shown, "the organization of a cerebral cortical area", which they gave examples of based on the primary visual cortex of the cat "corresponding to an old, diseased brain; a young, immature brain; and a normal adult brain" (Edelman and Tononi 2000: 131). The experiments testify to more entropy in the last and especially the first type of brain, which means that "the system can take a large number of states", but that age matters too (Edelman and Tononi 2000: 133).

Just as Oedipa highlights some information while other data remain incomprehensible, un-codified noise, so does the reader eliminate certain data s/he feels is not important for interpretation. On the other hand, they may just miss seeing it, insisting on the meticulous analysis of something chosen subjectively. George Levine notes: "We enter Pynchon's moments, as Oedipa does, discovering new and terrifying realities behind the conventions of reality - that is, of selection and election-we have been trained to believe in" (Levine 1986: 67-68). The difference is that the reader has the original text all along, while Oedipa is forced to rely on various interpretations, signs and symbols that change with time. Samuel Coale points out:

Pynchon's prose involves the density of his sentences and paragraphs. The amount of information he crams into a single sentence often boggles the mind, rife as they are with arcane information, sensuous images, imaginative riffs, and turbulent exposition (Coale 2005: 136).

Thus, interpretation is hindered.

The text constantly draws attention to the evasiveness of clues, language, representations, and truth:

Did she know why Driblette had put in those two extra lines that night? Had he even known why? No one could begin to trace it. A hundred hangups, permuted, combined-sex, money, illness, despair with the history of his time and place, who knew (LOT 162). 
Indeed, no one will ever know because Driblette committed suicide. One by one, the random pieces of the puzzle Oedipa hoped to gather dissipate, answering to the entropic pull, while her deliverers of testimony disappear: "They are stripping from me, she said subvocally - feeling like a fluttering curtain in a very high window, moving up to then out over the abyss - they are stripping away, one by one, my men" (LOT 152-153). They are very much like the "plucked albatross" (Pynchon 2000: 712) — Slothrop — the main character from Pynchon's masterpiece Gravity's Rainbow, who eventually disappears from the novel, facing the void of the abyss.

Oedipa wonders what would the Tristero's "terrible nakedness" deliver:

Would it smile, then, be coy, and would it flirt away harmlessly backstage, say goodnight with a Bourbon Street bow and leave her in peace? Or would it instead, the dance ended, come back down the runway, its luminous stare locked to Oedipa's, smile gone malign and pitiless; bend to her alone among the desolate rows of seats and begin to speak words she never wanted to hear? (LOT 54).

However, because the Tristero is not revealed, Oedipa never gets the message. Instead, it is disclosed that the system annihilates investigators who have come too close to proving its existence. The ending itself underlines the complexity and inconclusiveness of her search. Even as she participates at the auction, present at the moment when information should be available for her and for the readers, both she and the readers are denied the knowledge of who the bidder on lot 49 is:

[T] he mysterious, possibly demonic buyer who has come to bid on lot 49, which contains the anomalous Tristero stamps that set the whole plot in motion. Speculation is that he or she is someone from the Tristero [...]. Although both Oedipa and the reader would rather the buyer be either an avid philatelist or a mysterious, rebellious force that operates outside the closed system that is America, the book strongly suggests that the Tristero, as it now exists (if it now exists), is ominously linked to constellations of power and oppression (Chambers 1992: 98).

The title of the book itself underlines the importance of the final auctioning of the "anomalous" stamp collection, marking the novel's basic strategy, drawing attention to incompleteness and incomprehensibility in both content and form on larger and smaller scales of reality. The stamps are defined as "thousands of little colored windows into deep vistas of space and time: savannas teeming with elands and gazelles, galleons sailing west into the void, Hitler heads, sunsets, cedars of Lebanon, allegorical faces [...]" (LOT 45). The meaning of the stamps remains concealed, their contents are so divergent that their signification as a whole is unattainable because in Pynchon: "You never get to any of the underlying truth" (LOT 51). Yet, they serve as portholes to the real world, representing "a fractured, distorted, and "fractalized" miniaturization of a larger reality", offering no clues whatsoever to the Tristero enigma, and reflecting "a lack of core meaning and 
significance in all images, structures, and models in contemporary society" (Slethaug 2000: 113, 114).

The interplay of order and chaos within the collection, mirroring life itself, points at chaos theory and fractals, an infinite nesting of a pattern within a pattern, and recursions across scale. The imagery of stamps, as well as of Oedipa's adventures on her circular rides, her interpretations of Varo paintings, and the analysis of The Courier's Tragedy converge and illustrate the recursive structure of information and a connection that releases certain patterns. With reference to Prigogine and his abundant examples from chemistry, physics, and biology, where he extends the analysis of dissipative structures and chaos theory to social and cultural systems, it can be deduced that Pynchon's textual arrangements, the characters' social affiliations and language pertain to the category of systems enveloped in chaos theory. The multiplicity of patterns and their interactions (appearing as disorder) produce dramatic fluctuations and bifurcations within Oedipa's never-ending search. The system is far from equilibrium for "it is from the irreversible trajectory of the entropic universe that higher levels of structure emerge" (Mosko 2005: 33), evolving "spontaneously to a state of increased complexity" and "self-organization" (Prigogine 1997: 64, 70). The novel also suggests that chaos is ingrained in, or arises from, order and vice versa, that chaos produces order.

Pynchon's incessant use of puns and word play exposes the inextricable intricacy of open systems and the pluralism inherent in chaos theory, for the system itself produces new patterns as time goes by. This is a testament to the positive, creative side of the irreversibility of time. The novel's title attests of this "duplicity ... "Crying" is a pun; so is "lot". And even the number "49" hides religious meaning" (Malin 2000: 27-28). Lawrence Harvey questions if the number perhaps relates to "the 49 states in continental America" or "1849, the year of the Californian gold rush", when "the Tristero supposedly fled America" (Harvey 2013). Judith Chambers elaborates on the religious connotations of number 49:

There are 49 days between Easter and Pentecost, the celebration of the descent of the Holy Spirit upon the Apostles to speak in tongues and fill them with the Word; in Hinduism, the Bardo state, the time between death and rebirth, lasts for 49 days; and, finally, each scriptural message in the Talmud has 49 levels of interpretation (Chambers 1992: 116).

Recalling that Oedipa's journey commences and concludes on a Sunday with frequent references to the Christian liturgical calendar, we see that a cyclical "eternal return" is insinuated. This is in tune with the part of her search that demonstrates a recursive pattern. However, those are just indications of ergodic processes that Oedipa wishes would prevail and her aspirations to avoid death, entropy, and an ending. In reality, time is not reversible.

Oedipa also reveals the ambiguities, indeterminacy, and paradoxes of doctrines in general. Pynchon is certainly hinting at Heisenberg's Uncertainty Principle in this novel, as in his previous $V$. Oedipa's observation and sorting, as well as Herbert Stencil's (a character from $V$.) selecting and processing, 
cause indeterminacy of physical measurement, distorting the data while trying to sort it out; this occurs apart from the randomness inherent in the nature of matter. Oedipa discloses the functions and usefulness/uselessness of language through contemplative reflections:

Each clue that comes is supposed to have its own clarity, its fine chances for permanence. But then she wondered if the gemlike "clues" were some kind of compensation. To make up for her having lost the direct, epileptic Word, the cry that might abolish the night (LOT 118).

Meanings are not permanent, they are time and context-dependent, colliding, collapsing or germinating new meanings and connotations, providing indeterminacy, and making the system even more complex, its past states unattainable. Inklings without conclusion and signifiers that are just tracing on the verge of the signified but not quite there - maintain the communication system and make it at the same time promising and frustrating, productive (forming new patterns with time) and unproductive (forever losing touch with its "old" states), while Oedipa strives for "some promise of hierophany" (LOT 31), some meaning and truth.

Thomas Moore argues that this novel displays "the printed-circuit-like streets of the closed system of San Narciso/America" (Moore 1987: 118), alluding to Oedipa's observation from the hilltop of San Narciso: the "printed circuit. The ordered swirl of houses and streets" (LOT 24). Oedipa herself assimilates the "prisoners in the top room of a circular tower" (LOT 21) from Varo's painting she once saw. As Cornis-Pope notes, Oedipa "cannot fully offset the paranoid concept of a "closed circuit" universe that still haunts her imagination" (Cornis-Pope 2001:106). However, it seems that there are many systems interacting within the novel, crossing borders and thus causing new systems to emerge, so that the system is really open and not closed. Moore further on admits that: "No system anywhere short of the total Gibbsian cosmos can be regarded as forever closed: they may always open or be opened out to larger systems" (Moore 1987: 164), which is again the result of the time passing in one direction. There is a symbolic closure in Oedipa's circular bus rides after leaving Nefastis's house through Oakland, San Francisco, and Berkeley, stopping in front of Nefastis's home again, "back where she'd started" (LOT 131). Within this recursive pattern, she commutes and corresponds with an array of marginalized individuals, acquiring mind-boggling information that does not help her teleological quest for the truth. On the contrary, the monumental data that Oedipa assembles consist of shifting fragments for the input is highly inconclusive and ambivalent. The evidence and remnants vanish, and the people that have volunteered to speak withdraw, perish, and even die, exhibiting the entropic pull. Like "Pynchonian characters, undifferentiated and mirrored ad infinitum", each information that Oedipa comes across "is little more than a cipher of a progressive, irreversible dematerialization" (Grgas 1989: 292).

The wish for the closure of the system can also be identified in Oedipa's teleological, detective-like search. It "beckons closure through its epistemic and ultimately totalitarian orientation" (Harvey 2013) for "everything she saw, 
smelled, dreamed, remembered, would somehow come to be woven into The Tristero" (LOT 81), and "[e]very access route to the Tristero could be traced also back to the Inverarity estate" (LOT 170). This means that Oedipa is back at the beginning again. All the codes, allusions, symbols, and messages are interconnected and flow either from the Tristero or from Pierce (Oedipa is not sure which one), juxtaposing and collapsing one into another. Thus, we observe the apparent possibility of a closure. Yet, the closure is forever deferred as Oedipa (and the readers) becomes knotted in a semiotic circle of interpretation, persisting to investigate in what seems an empty loop as far as meaning is concerned. She discovers "other revelations which now seemed to come crowding in exponentially, as if the more she collected the more would come to her" (LOT 81). The proliferation of signs and their perpetual reference to other signs overwhelms the text with information. The meaning is constantly refashioned and never resolved into a single meaning for "interpretation is carried to infinity and never encounters anything to interpret that is not already itself an interpretation. The signified constantly reimparts the signifier, recharges it or produces more of it" (Deleuze and Guattari 1987: 114). However, all this activity keeps the system operative: as much energy disperses as emerges through other thresholds. New information materializes because time is irreversible.

Pynchon sustains that the second law of thermodynamics is not violated, entropy proceeds, and time's arrow is facing the future. However, the randomized energy (or waste) that one system dissipates into the surrounding environment is used by another system ${ }^{3}$ (just like the children used "Tristero" that became "Tristoe"), thus bringing order out of chaos. This means there is a "natural demon" existing all along; except, it is not what Maxwell, Nefastis, or Oedipa figured it should be, because it is not a perpetuum mobile. It operates in mysterious ways, closely connected to nonlinear, far from equilibrium systems and chaos theory.

The metaphor of chaotic systems and their self-organization, which corroborate the "miracle" of life, is contained within the story of the deaf-mute convention that Oedipa engages in by chance. After her twenty-four-hour crusade through San Francisco, Oedipa is exhausted and finally enters her hotel where she is swept up by the crowd into the ballroom and waltzes with one of the delegates. She observes the rest of the deaf-mute crowd whirl to the sound of silence, each couple dancing to "whatever was in the fellow's head: tango, two-step, bossa nova, slop" (LOT 131). She anticipates collisions, yet there are none for each couple follows a "mysterious consensus" (LOT 131), gracefully attuning into the whole. The artistry and "grace of the dance, despite the absence of conventional arrangement" (Kharpertian 1990: 91) make Oedipa think of "some unthinkable order of music, many rhythms, all keys at once, a choreography in which each couple meshed easy, predestined. Something they all heard with an extra sense atrophied in herself" (LOT 131). Even though their moves should be completely disordered, stemming from their inability to hear or utter sounds, it seems that their system as a whole has evolved into a complexity beyond Oedipa's reach.

\footnotetext{
${ }^{3}$ Physicists John Briggs and David Peat give the example of systems such as the dung beetle or the mitochondria in human cells which transform wastes from fermented food molecules into ATP, a molecule that stores energy; substantiating the idea that "dissipative structures" take advantage of entropy (Briggs 1989: 139).
} 


\section{Conclusion}

As illustrated in the analysis of The Crying of Lot 49, Pynchon's focus is on the irreversibility of time, perpetual change and entropy, acknowledging its negative, dissipative outcome. Oedipa tries to regulate these phenomena by administering her unique capacities as an information sorter (demon), aiding the collapsing worlds/systems with the input of external energy. Even though her sorting keeps the variety of systems existent and vibrant (although changed), enabling new forms of order to originate out of disorder (in accord with chaos theory), the emphasis the author denotes is on the excess of information, their mutual interactions and the loss of meaning which weigh down Oedipa and possibly the reader. It is typical of Pynchon to concentrate more on the detrimental, entropic part of the time's arrow. In his Introduction to Slow Learner he explains:

Since I wrote this story ["Entropy"], I have kept trying to understand entropy, but my grasp becomes less sure the more I read. [...] But the qualities and quantities will not come together to form a unified notion in my head. It is cold comfort to find out that Gibbs himself anticipated the problem, when he described entropy in its written form as "far-fetched ... obscure and difficult of comprehension". When I think about the property nowadays, it is more and more in connection with time, the human one-way time we're all stuck with locally here, and which terminates, it is said, in death. Certain processes, not only thermodynamic ones but also those of a medical nature, can often not be reversed. Sooner or later we all find this out, from the inside. (Pynchon 1984: 14-15).

It is also the case that entropy and chaos (traditionally perceived as disorder) demonstrate the capacity for action and intervention, for new forms of order and self-organization (as is the case with the deaf-mute dancing patterns and harmony). They accommodate a highly dynamic, complex, indeterminate, and nonlinear world of interconnected structures and emergent potentialities. These are teeming with unpredictable evolutions and correspond to Prigogine's "nonequilibrium" systems that can evolve spontaneously into complex ordering, bringing order out of chaos, which is "the outcome of irreversible processes" (Prigogine 1997: 64). Although changed with the passage of time, the systems that Oedipa tries to unravel are at least preserved through those transformations. However, Pynchon focuses more on the negative aspects of time rushing forward, insisting on the overload of information, inability to make sense of it and failure to keep it intact.

The author depicts chaotic behavior within various systems, but as Briggs and Peat remark, the word "chaos" is used in two distinct, although sometimes interchangeable ways (Briggs 1989: 136). One is the passive chaos of equilibrium and maximum entropy, representing the "heat death" as Clausius predicted. The other chaos is active and energetic, far-from-equilibrium, out of which new systems emerge - the everlasting change/progress that keeps humans alive. Thus, there are both a pessimistic and an optimistic lineage in Pynchon's novel enacting simultaneously, with more emphasis on the negative aspects of 
temporality. As with some arrangements of chaos and complexity theory, new forms of order emanate out of disorder, but as with classical entropy theory, dynamic systems decay and disintegrate, and time is still irreversible.

\section{References}

Brigg P (2002) The Span of Mainstream and Science Fiction: A Critical Study of a New Literary Genre. Jefferson, NC \& London: McFarland \& Company, Inc.

Briggs J, Peat D (1989) Turbulent Mirror: An Illustrated Guide to Chaos Theory and the Science of Wholeness. New York: Harper \& Row Publishers.

Brown C (2003) Waste, Death, and Destiny: Heterotopic Scenarios in The Crying of Lot 49. In N Abbas (ed.), Thomas Pynchon: Reading from the Margins (154-161). Fairleigh Dickinson University Press \& London: Associate University Press.

Brownlie A (2000) Thomas Pynchon's Narratives: Subjectivity and Problems of Knowing. New York: Peter Lang.

Chambers J (1992) Thomas Pynchon. New York: Twayne Publishers.

Coale SC (2005) Paradigms of Paranoia: The Culture of Conspiracy in Contemporary American Fiction. Tuscaloosa: The University of Alabama Press.

Copestake I (2005) "Our Madmen, Our Paranoid": Enlightened Communities and the Mental State in Mason \& Dixon. In E Wall Hinds (ed.), The Multiple Worlds of Pynchon's Mason \& Dixon: Eighteenth-Century Contexts (171-184). Rochester: Camden House.

Cornis-Pope M (2001) Narrative Innovation and Cultural Rewriting in the Cold War and After. New York: Palgrave.

Davies P (1995) About Time: Einstein's Unfinished Revolution. New York, London, Toronto, Sydney, Tokyo, Singapore: Simon \& Schuster.

Deleuze G, Guattari F (1987) A Thousand Plateaus: Capitalism and Schizophrenia. Trans. B Massumi. Minneapolis: University of Minnesota Press.

Edelman G, Tononi G (2000) A Universe of Consciousness: How Matter Becomes Imagination. New York: Basic Books.

Grgas S (1989) Gravity's Rainbow and Ihab Hassan's “Catena” of Postmodernism. Razdio Filoloških Znanosti (18), 1988-1989 (283-305). Filozofski Fakultet Zadar.

Harvey L (2013) To Cry from Within or Without? Pynchon and the Modern - Postmodern Divide. Orbit: Writing Around Pynchon. 2 (1). https://www.pynchon.net/articles/ 10.7766/orbit.v2.1.47/ (accessed 8 March 2016).

Hayles NK (1991) A Metaphor of God Knew How Many Parts: The Engine that Drives The Crying of Lot 49. In P O'Donnell (ed.), New Essays on The Crying of Lot 49 (97-125). Cambridge University Press.

Hayles NK (1990) Chaos Bound: Orderly Disorder in Contemporary Literature and Science. Ithaca and London: Cornell University Press.

Hite M (1983) Ideas of Order in the Novels of Thomas Pynchon. Columbus: Ohio State University Press.

Holton GJ (1973) Introduction to Concepts and Theories in Physical Science, $2^{\text {nd }}$ edition revised and with new material by SG Brush. Reading, Mass.: Addison-Wesley.

Kharpertian TD (1990) A Hand to Turn the Time: The Menippean Satires of Thomas Pynchon. London \& Toronto: Associated University Press.

Leigh DJ (2008) Apocalyptic Patterns in Twentieth-Century Fiction. Notre Dame, Indiana: University of Notre Dame. 
Levine G (1986) Risking the Moment. In H Bloom (ed.), Modern Critical Views: Thomas Pynchon (59-77). New York, New Haven, Philadelphia: Chelsea House Publishers.

Mackey AD (1980) The Rainbow Quest of Thomas Pynchon. San Bernardino, California: The Borgo Press.

Malin I (2000) Foreshadowing the Text. In B Horvath, I Malin (eds.), Pynchon and Mason \& Dixon (27-42). London: Associated University Presses \& Newark: University of Delaware Press.

Mangel A (1976) Maxwell's Demon, Entropy, Information: The Crying of Lot 49. In G Levine, D Leverenz (eds.), Essays on Thomas Pynchon (87-99). Boston, Toronto: Little, Brown and Company.

Maxwell JC (1871) Theory of Heat. London \& New York: Longmans, Green.

Moore T (1987) The Style of Connectedness: Gravity's Rainbow and Thomas Pynchon. Columbia: University of Missouri Press.

Mosko MS (2005) Introduction: A (Re)Turn to Chaos: Chaos Theory, the Sciences, and Social Anthropological Theory. In MS Mosko, FH. Damon (eds.), On the Order of Chaos: Social Anthropology and the Science of Chaos (1-46). New York and Oxford: Berghahn Books.

Prigogine I (in collaboration with I Stengers) (1997) The End of Certainty: Time, Chaos, and the New Laws of Nature. New York, London, Toronto, Sydney, Singapore: The Free Press.

Pynchon T (1963) V. Philadelphia and New York: J.B. Lippincott Company.

Pynchon T (1990) The Crying of Lot 49. New York: Harper \& Row.

Pynchon T (2000) Gravity's Rainbow. Vintage.

Pynchon T (1984) Slow Learner: Early Stories, Boston, Toronto: Little, Brown and Company.

Schaub T (1981) A Gentile Chill, An Ambiguity: The Crying of Lot 49. In R Pearce (ed.), Critical Essays on Thomas Pynchon (51-68). Boston, Massachusetts: G.K. Hall \& co.

Shannon CE (1948) A Mathematical Theory of Communication. Reprinted with corrections from The Bell System Technical Journal, Vol. 27, pp. 379-423, 623-656, July, October, 1948. Accessed 23 May 2016 (pp. 1-55): http://worrydream.com/refs/S hannon\%20-\%20A\%20Mathematical\%20Theory\%20of\%20 Communication.pdf

Slethaug G (2000) Beautiful Chaos: Chaos Theory and Metachaotics in Recent American Fiction. Albany: State University of New York Press.

York Blaine D (2003) Death and The Crying of Lot 49. In N Abbas (ed.), Thomas Pynchon: Reading from the Margins (51-70). Fairleigh Dickinson University Press \& London: Associate University Press.

Whitehead AN (1929) The Aims of Education \& Other Essays. New York: The MacMillan Company. 
